\title{
Por Que Análise Real na Licenciatura? Um Paralelo entre as Visões de Educadores Matemáticos e de Matemáticos
}

\author{
Why Real Analysis in Mathematics Teacher Education? A Comparison \\ Between Mathematics Educators' and Mathematicians' Views
}

\author{
Plinio Cavalcanti Moreira* \\ Carlos Roberto Vianna**
}

\begin{abstract}
Resumo
Neste trabalho analisam-se as respostas apresentadas por 18 educadores matemáticos a um questionário sobre a ementa e o papel da disciplina Análise Real nos cursos de Licenciatura em Matemática e traça-se um paralelo com as respostas dadas por matemáticos a esse mesmo questionário em 2005. Os educadores matemáticos são pesquisadores selecionados entre os que orientaram tese de doutorado entre 2006 e 2011 em instituições universitárias brasileiras. Os procedimentos metodológicos foram os mesmos utilizados na análise das respostas dos matemáticos: elas foram submetidas a um processo de unitarização para a construção de categorias, segundo a abordagem metodológica da Análise de Conteúdo. Descrevem-se duas categorias que sintetizam os argumentos dos educadores matemáticos em favor da obrigatoriedade da disciplina no curso de licenciatura e comparam-se esses argumentos com os obtidos no estudo com os matemáticos, publicado em 2005. Os resultados mostram que, em geral, os argumentos dos dois grupos convergem, embora sutis diferenças de percepção do papel da Análise Real na Licenciatura tenham sido identificadas.
\end{abstract}

Palavras-chave: Educação Matemática. Licenciatura. Formação Matemática do Professor. Saber Docente. Análise Real.

\begin{abstract}
This article presents the answers given by 18 mathematics educators to a questionnaire about the role of a Real Analysis course in mathematics teacher education at university level, comparing them with the answers given by mathematicians to the same questionnaire in 2005. Participants of this research were selected among doctorate thesis supervisors in Mathematics Education, in the time period between 2006 and 2011, working at leading universities in Brazil. The data were analyzed according to the Content Analysis' methodological approach. We describe two categories of arguments that emerged from the data, according to which a Real Analysis course should be a mandatory part of the curriculum in prospective mathematics teacher education and compare them with the ones obtained in the study with the mathematicians in 2005 . The results indicate a general convergence in the views of both professional groups, although subtle differences were detected.
\end{abstract}

Key words: Mathematics Education. Mathematics Teacher Education. Teacher Knowledge. Real Analysis.

" Doutor em Educação pela Faculdade de Educação (FaE) da Universidade Federal de Minas Gerais (UFMG). Professor do Departamento de Matemática da Universidade Federal de Ouro Preto (UFOP), Ouro Preto/MG, Brasil. Endereço para correspondência: Departamento de Matemática/UFOP, Campus Morro do Cruzeiro, s/n, Ouro Preto/MG, CEP: 35.400-000, Brasil. E mail: plinio@ufmg.br

Doutor em Educação pela Faculdade de Educação (FE) da Universidade Federal do Estado de São Paulo (USP). Professor do Departamento de Matemática da Universidade Federal do Paraná (UFPR), Curitiba/PR, Brasil. Endereço para correspondência: Departamento de Matemática - UFPR, Caixa Postal 19081, Curitiba/PR, CEP 81531-990, Brasil. E-mail: carlos_r2v@yahoo.com.br 


\section{Introdução}

O desenvolvimento do debate sobre o conhecimento matemático que deve fazer parte da formação do professor de matemática da Educação Básica tem trazido à tona, especialmente a partir dos anos 1980, algumas questões teóricas que se referem às relações entre os saberes demandados pela prática docente escolar e os saberes trabalhados nos cursos de licenciatura. Além disso, também tem sido objeto de estudo e de debate o papel da própria prática na produção dos saberes profissionais docentes (SHULMAN, 1986,1987; TARDIF, 2002; BALL, THAMES e PHELPS, 2008).

Como observado em Moreira, Cury e Vianna (2005), a comunidade científica dos matemáticos desempenha um papel importante nessa discussão, fundamentalmente pela influência que exerce no desenho dos currículos e no desenvolvimento das atividades de formação dos cursos de licenciatura em matemática das grandes universidades do Brasil. Outro grupo importante nesse debate é o dos educadores matemáticos (nomeamos assim, neste texto, os pesquisadores na área de Educação Matemática) que, além de também influenciarem a concepção e execução dos projetos curriculares de formação do professor no Brasil, têm se dedicado intensamente a pesquisas e estudos sobre os grandes temas pertinentes à formação de professores de matemática por mais de quatro décadas. Por outro lado, os professores de matemática da Escola Básica e os alunos da licenciatura em matemática também constituem importantes grupos a serem envolvidos nessa discussão.

Em termos de ações da comunidade de pesquisa em Educação Matemática, têm sido promovidos encontros de discussão sobre a formação inicial do professor de matemática da Educação Básica, buscando-se o diálogo com pesquisadores internacionais e com os próprios matemáticos brasileiros a respeito do tema (ver Boletim 21 da SBEM, fevereiro de 2013). Contribuindo para o debate, publicamos um primeiro artigo (Moreira, Cury e Vianna, 2005), no qual procuramos recolher, tornar explícitas, analisar e trazer a público as opiniões de alguns dos membros da comunidade dos matemáticos do Brasil sobre o papel da disciplina Análise Real nos cursos de licenciatura em matemática. Agora, neste segundo trabalho, procuramos recolher as visões, sobre a mesma questão, de educadores matemáticos em atuação no Brasil, comparando-as com as visões dos matemáticos, descritas no estudo de 2005. Num terceiro momento, esperamos trazer a público, em forma semelhante, as visões dos professores de matemática da Educação Básica (e dos licenciandos) sobre essa questão.

No artigo de 2005, referido acima, escrevemos: 


\begin{abstract}
A disciplina Análise Real é (...) um dos pilares da formação do bacharel em matemática. Ela pode ser vista (...) como uma das formas de introdução dos futuros matemáticos a conceitos, métodos, técnicas e valores próprios da matemática avançada, além de servir de base para a Análise no $\mathrm{R}^{\mathrm{n}}$ e (...) para estudos mais gerais, envolvendo outros espaços e estruturas (...). No Brasil, os cursos de licenciatura em matemática (...) tiveram, por muitos anos, uma estrutura curricular que, em geral, incluía disciplinas de Cálculo, Álgebra e Geometria Analítica no início do curso e, nos últimos semestres, aquelas que são trabalhadas em um nível mais alto de formalização e rigor, como a Topologia e a Análise Real. O Conselho Nacional de Educação (...) estabeleceu que 800 horas (...) da grade curricular devem ser dedicadas à prática (...) (estágios e atividades complementares relacionadas diretamente com a prática docente escolar). $\mathrm{Na}$ elaboração de novos projetos pedagógicos para os cursos de licenciatura em matemática, põe-se em questão a permanência de algumas disciplinas na grade curricular e torna-se necessária a explicitação do papel que estas efetivamente desempenham na preparação do licenciando para a futura prática profissional na escola básica. Considerando que, no curso de licenciatura, já há disciplinas que incluem o estudo das funções reais (como, por exemplo, o Cálculo Diferencial e Integral), pode-se perguntar: de quais tópicos deveria tratar a disciplina Análise Real e com que tipo de abordagem? Deveria ela ser obrigatória no curso de licenciatura? Por quê? (MOREIRA, CURY, VIANNA, 2005, p.12-13).
\end{abstract}

Tais perguntas foram as que propusemos aos matemáticos e que agora reapresentamos a oitenta educadores matemáticos, selecionados entre aqueles que orientaram trabalhos de doutorado em Educação Matemática, no período 2006-2011. Como no caso dos matemáticos, os educadores matemáticos foram contatados através de seus endereços eletrônicos. Incluímos, na próxima seção, a íntegra do questionário enviado.

Como observamos no artigo de 2005, é importante ressaltar que o nosso estudo se configura como uma pesquisa de caráter exploratório e que as perguntas, estimulando os participantes a pensar e escrever sobre o papel da Análise Real na formação inicial do professor de Matemática, induzem manifestações de natureza subjetiva. Ainda que alguns dados quantitativos sejam apresentados neste artigo, eles também, como no caso dos matemáticos, não devem ser vistos como índices percentuais aplicáveis à comunidade dos educadores matemáticos, até porque o retorno que obtivemos dos educadores matemáticos contatados não foi superior a $35 \%$ da amostra, como explicitado a seguir.

Dos 80 educadores matemáticos a quem enviamos o questionário, 28 responderam, mas, dentre estes, dez não se dispuseram a contribuir para a pesquisa, por variadas razões, desde não acreditar nesse tipo de pesquisa (restrições de natureza metodológica) até por não estar com "a menor vontade" de pensar no assunto. Alguns disseram que não se sentiam capacitados a opinar, seja por não possuírem experiência de trabalho com a disciplina Análise Real na licenciatura, seja por não terem formação adequada. Observamos, de passagem, que os números correspondentes, entre os matemáticos, na pesquisa de 2005, foram os seguintes: dos 80 matemáticos contatados, recebemos resposta de 31 e nenhum deles alegou não estar 
habilitado a comentar o assunto. Esse é um dos aspectos que podem ser observados ao fazermos um paralelo entre as visões dos educadores matemáticos e as dos matemáticos.

No geral, para facilitar a identificação das diferenças e das similaridades entre as visões sobre o tema desses dois grupos de profissionais, decidimos construir este artigo a partir da mesma estrutura do artigo de 2005, o que obriga, em alguns casos, uma dose de repetição quando retomamos dados e conclusões da pesquisa anterior. Ponderando "prós e contras", achamos que, apesar dessas repetições, nossa opção de construção do texto é interessante, no sentido de facilitar o destaque das convergências e/ou divergências entre as visões desses dois grupos de profissionais que exercem, cada um a seu modo, grande influência sobre o desenho e a implementação do currículo da licenciatura em matemática no Brasil.

No caso dos educadores matemáticos, ficamos, então, com 18 respostas efetivas. Tendo em vista que todos os pesquisadores contatados são membros destacados da comunidade da Educação Matemática que atua no Brasil, entendemos que suas respostas trazem contribuições importantes para o debate, ainda que não expressem, como já observado, posições que possam ser generalizadas para a comunidade como um todo.

\section{Os resultados}

Antes dos resultados, apresentamos a íntegra do questionário que enviamos em 2011 aos sujeitos da pesquisa, com pequenas modificações em relação ao questionário enviado aos matemáticos em 2005. Trata-se de uma breve apresentação da pesquisa, seguida de três questões.

\section{Prezado(a) colega:}

Nós, os professores Carlos Roberto Vianna (Departamento de Matemática da Universidade Federal do ParanáUFPR) e Plinio Cavalcanti Moreira (Departamento de Matemática da Universidade Federal de Ouro PretoUFOP), estamos realizando uma pesquisa sobre a composição da grade curricular dos cursos de Licenciatura em Matemática no Brasil. Nesta segunda etapa do trabalho, estamos interessados em conhecer a visão dos educadores matemáticos a respeito do papel da disciplina Análise na Reta (ou Análise Real) na formação do licenciado (numa primeira etapa, procuramos conhecer as opiniões dos matemáticos). Na impossibilidade de ouvir todos os membros da comunidade dos educadores matemáticos, selecionamos uma amostra composta por pesquisadores ativos da área que atuam ou atuaram em Programas de Pós-Graduação no Brasil e que tiveram orientações de doutorado na área de Educação Matemática concluídas nos últimos 5 anos.

Agradecemos a sua colaboração no sentido de responder às três questões seguintes (por gentileza, responda dando um reply a este mail).

1. Assinale os itens que, na sua opinião, deveriam ser trabalhados numa disciplina de Análise na Reta para a Licenciatura em Matemática (se for o caso, acrescente outros):

( ) O conjunto dos números reais como corpo ordenado completo

( ) Topologia da reta 
( ) Sequências e séries de números reais

( ) Continuidade de funções reais de variável real

( ) Derivada de funções reais de variável real

( ) Integral (Riemann) de funções reais de variável real

2. Assinale o(s) livro(s) que você recomendaria para a disciplina Análise na Reta do curso de Licenciatura em Matemática (se for o caso, acrescente outros):

( ) Curso de Análise (volume I) ou Análise Real vol. I - Elon L. Lima

( ) Introdução à Análise Real - Elon L. Lima

( ) Análise I - Djairo G. de Figueiredo

( ) Análise Matemática para a Licenciatura - Geraldo Ávila

3. Pense na disciplina Análise na Reta com uma ementa dada, aproximadamente, pelos tópicos que você selecionou na pergunta 1 e uma abordagem semelhante à da bibliografia que você indicou na pergunta $2 . \mathrm{Na}$ sua opinião, todo curso de Licenciatura em Matemática deveria ter essa disciplina como obrigatória? ( ) Sim ( ) Não

Se lhe coubesse defender o SIM ou o NÃO, que argumentos você apresentaria?

Fonte: os autores (2016)

Nos quadros abaixo estão sintetizadas as respostas às questões 1 e 2 e à primeira parte da questão 3. Para o tratamento das respostas à parte aberta da questão 3, foram utilizados procedimentos da análise de conteúdo, a que nos referiremos com algum detalhe mais adiante.

\section{QUESTÃO 1}

Assinale os itens que, na sua opinião, deveriam ser trabalhados numa disciplina de Análise na Reta para a licenciatura em matemática.

\begin{tabular}{|l|c|c|}
\hline \multicolumn{1}{|c|}{ Itens assinalados } & $\begin{array}{c}\text { Número de } \\
\text { indicações }\end{array}$ & (em 18) \\
\hline O conjunto dos números reais como corpo ordenado completo & 16 & 88,9 \\
\hline Topologia da reta & 14 & 77,8 \\
\hline Continuidade de funções reais de variável real & 12 & 66,6 \\
\hline Derivada de funções reais de variável real & 8 & 44,4 \\
\hline Integral (Riemann) de funções reais de variável real & 7 & 38,9 \\
\hline $\begin{array}{l}\text { História da M20 (M20 significa, ao que entendemos, a Matemática na forma que } \\
\text { tomou a partir da segunda metade do século 19) }\end{array}$ & 5,5 \\
\hline $\begin{array}{l}\text { Notas históricas acerca de tópicos do programa da disciplina } \\
\text { Tópicos relativos ao trabalho com a disciplina no Ensino Médio }\end{array}$ & 1 & 5,5 \\
\hline Funções de variável complexa (“apenas um mostrar que existem”) & 1 & 5,5 \\
\hline $\begin{array}{l}\text { Construção dos números reais (partindo da construção dos naturais, de forma } \\
\text { axiomática e construtiva - ver Frege e Mank) }\end{array}$ & 1 & 5,5 \\
\hline $\begin{array}{l}\text { Uma construção dos números reais a partir de cortes ou de sequencias ou de } \\
\text { intervalos (basta uma). }\end{array}$ & 1 & 5,5 \\
\hline
\end{tabular}

Quadro 1 - Respostas da questão 1, com número de indicações e percentagens. Fonte: Os autores (2016)

Observações feitas por alguns dos respondentes, relativas à Questão 1: 
a) A definição de limite deve ser fundada no cálculo proposicional, explicitando os quantificadores (1 respondente)

b) O teorema do valor intermediário deve ser rigorosamente tratado (1 respondente)

c) Ênfase nos aspectos conceituais e semânticos (1 respondente)

d) A questão não é tanto os conteúdos, mas a forma de abordá-los (6 respondentes)

\section{QUESTÃO 2}

Indique o(s) livro(s) que você recomendaria para a disciplina Análise na Reta em um curso de Licenciatura em Matemática.

\begin{tabular}{|l|c|c|}
\hline \multicolumn{1}{|c|}{ Livros indicados } & Indicações & \% \\
& & (em 18) \\
\hline Análise Matemática para a Licenciatura - Geraldo Ávila & 12 & 66,6 \\
\hline Análise I - Djairo G. de Figueiredo & 2 & 11 \\
\hline Análise Real (volume I) - Elon L. Lima & 1 & 5,5 \\
\hline Introdução à Análise Real - Elon L. Lima & 1 & 5,5 \\
\hline Nenhum deles & 1 & 5,5 \\
\hline Os do Elon não. Os outros não conheço & 1 & 5,5 \\
\hline Cálculo - Spivak & 1 & 5,5 \\
\hline Introducción al Calculo y al Analysis Matemático (Courant, Fritz) & 1 & 5,5 \\
\hline Lições de Álgebra e Análise - Caraça & 1 & 5,5 \\
\hline Conceitos Fundamentais da Matemática - Caraça & 5,5 \\
\hline Aritmética dos Números Reais - Pasterlini & 1 & 5,5 \\
\hline
\end{tabular}

Quadro 2 - Respostas da questão 2, com número de indicações e percentagens. Fonte: Os autores (2016).

\section{QUESTÃO 3}

Pense na disciplina Análise na Reta com uma ementa dada, aproximadamente, pelos tópicos listados na pergunta 1 e uma abordagem semelhante à da bibliografia relacionada na pergunta 2. Na sua opinião, todo curso de Licenciatura em Matemática deveria ter essa disciplina como obrigatória?

\section{Respostas:}

Sim: $15(83,5 \%)$

Não: zero

Não necessariamente (poderia ser incluída em outras disciplinas): 1 (5,5\%) 
Não responderam: $2(11 \%)$

\section{OBSERVAÇÕES:}

1. Nos quadros referentes às questões 1 e 2 , as percentagens foram calculadas sobre o número total de respondentes (18), ainda que cada um deles tenha assinalado mais de um item ou indicado mais de um livro.

2. As percentagens indicadas nas respostas à questão 3 também foram calculadas sobre o total de 18 respondentes.

3. Ninguém, entre os educadores matemáticos, manifestou a opinião de que a disciplina Análise Real NÃO deveria ser obrigatória no curso de licenciatura.

A seguir, apresentamos alguns elementos da metodologia utilizada para a análise da segunda parte (aberta) da questão 3. Lembramos que essa pergunta tem duas partes e as respostas da primeira parte foram sintetizadas acima. Na sequência deste texto vamos analisar e discutir os argumentos apresentados na segunda parte da pergunta. $\mathrm{O}$ enunciado completo desta pergunta é o seguinte:

Pense na disciplina Análise na Reta com uma ementa dada, aproximadamente, pelos tópicos que você selecionou na pergunta 1 e uma abordagem semelhante à da bibliografia que você indicou na pergunta 2. Na sua opinião, todo curso de Licenciatura em Matemática deveria ter essa disciplina como obrigatória? ( ) Sim ( ) Não

Se lhe coubesse defender o SIM ou o NÃO, que argumentos você apresentaria?

As respostas foram trabalhadas segundo a análise de conteúdo, metodologia que é, segundo Bardin (1979),

Um conjunto de técnicas de análise das comunicações visando obter, por procedimentos e objectivos de descrição do conteúdo das mensagens, indicadores (quantitativos ou não) que permitam a inferência de conhecimentos relativos às condições de produção/recepção (variáveis inferidas) destas mensagens (p. 42).

Descrevemos, em Moreira, Cury e Vianna (2005), os detalhes referentes aos procedimentos metodológicos adotados na análise e categorização das respostas dadas a essa parte da terceira questão do Questionário. Assim, pedimos licença para remeter o leitor interessado nesses detalhes ao artigo referido acima. No entanto, repetimos aqui o seguinte:

Insistimos na observação de que toda leitura envolve interpretações, que podem ou não ser compartilhadas por outros leitores ou pelos próprios autores dos textos. Assim, as categorias construídas estão certamente impregnadas dessas interpretações 
e, por isso, julgamos importante reproduzir, junto com a descrição de cada uma delas, algumas unidades de sentido destacadas no processo de unitarização dos textos das respostas. Esperamos, com esse procedimento, tornar mais transparentes as nossas interpretações e facilitar uma avaliação, por parte do leitor, da consistência das categorias construídas (MOREIRA, CURY, VIANNA 2005, p. 19-20).

Enumeramos os respondentes de 1 a 18 , sendo que quatro deles não responderam a segunda parte da questão 3 e um respondeu "não necessariamente", apenas levantando possibilidades alternativas, sem defender o sim ou o não. Assim, no conjunto das 13 respostas defendendo um curso de Análise Real obrigatório na Licenciatura em Matemática, selecionamos 20 unidades de discurso que julgamos relevantes para os objetivos da pesquisa. Sintetizamos essas unidades em duas grandes categorias, as quais são descritas e comentadas adiante. Por fim, observamos que, como certamente notará o leitor, as unidades de discurso selecionadas ficaram um tanto ou quanto alongadas, tendo em vista que a defesa do sim se referia à ementa e bibliografia indicadas por cada um dos respondentes, o que nos levou a tentar, sempre que possível, tornar mais claras as conexões entre o essencial da ementa proposta pelo respondente e seus argumentos em favor da obrigatoriedade da disciplina.

Enviamos a categorização dos dados aos 18 educadores matemáticos que responderam ao questionário, convidando cada um deles a avaliar a síntese resultante e o modo como foram situadas as suas respostas entre as categorias construídas, não tendo havido registro de nenhuma objeção por parte dos respondentes.

\section{As categorias}

\section{Categoria 1}

A disciplina deve ser obrigatória no curso de licenciatura porque ela é fundamental para que os licenciandos tenham um contato mínimo com a matemática superior, o que constitui um elemento central na construção de um ponto de vista sobre a matemática moderna. $O$ aluno da licenciatura precisa conhecer a natureza do pensamento matemático, seus modos de proceder, suas demonstrações, a forma como a matemática organiza-se em conhecimento específico, precisa ter uma cultura matemática.

Oito educadores matemáticos (um pouco mais de 60\% dos 13 que responderam a esta parte da questão 3) apresentaram argumentos nessa Categoria 1, num total de 9 unidades de discurso $(45 \%)$ das 20 destacadas. Note-se, entretanto, que três educadores matemáticos apresentaram argumentos nas duas categorias. A seguir, indicamos, a título de ilustração e fundamentação, exemplos de algumas unidades que vieram a constituir a Categoria 1, com indicação dos respectivos respondentes (identificados por um código numérico): 
1. Acho fundamental para a apropriação de uma cultura matemática que o aluno tenha uma boa formação em Análise. A disciplina, em geral, é muito exigente, pois lida com grandes rupturas no pensamento matemático. Isso a meu ver é inevitável, pois sua raiz é epistemológica. Não é a toa que a formalização dos números reais, das noções de função, continuidade e limite exigiram tanto tempo na própria história da matemática (Respondente 2).

2. Um bom curso de análise na licenciatura deveria, na minha opinião, permitir aos alunos enfrentar essa ruptura, tomar consciência desse enfrentamento e refletir sobre como preparar o terreno para que os alunos do Ensino Médio possam também viver esse processo. Por isso, eu incluiria os itens relativos às notas históricas (o que permitiria ao aluno perceber que o processo vivido por ele não é pessoal apenas, mas fruto da natureza do conhecimento com o qual está lidando) (Respondente 2).

3. A abordagem da Análise traz para o licenciando uma maneira de lidar com conhecimentos matemáticos, a meu ver, bem diferente daquela que lhe confere o Cálculo, e o tratamento concedido à matemática da Educação Básica. Acho essa experiência importante, se for proporcionada com essa perspectiva: a apropriação de um outro modo de matematicar - um modo de viver a cultura matemática acadêmica, destacando-se os valores que permeiam, sustentam e conferem sentido às decisões que se tomam na configuração das elaborações e procedimentos nesse campo, inclusive em comparação com outras possibilidades de abordagem (Respondente 3 ).

4. Conceitos formais em um curso de Licenciatura deveriam ser apresentados de modo a expor sua necessidade ou propósito na construção do conhecimento matemático, seu poder e limitações. Penso em uma espécie de "meta-curso", as atividades a serem desenvolvidas deveriam ser diferentes daquelas desenvolvidas para um curso de bacharelado, uma vez que os motivos para a apresentação das ferramentas matemáticas seriam diferentes (Respondente 4).

5. A disciplina de Análise é fundamental para que os licenciandos tenham um contato mínimo com a matemática superior, o que constitui um elemento central na construção de um ponto de vista sobre o conjunto da matemática moderna, o que não é fornecido por nenhuma outra disciplina. Um argumento em favor disto é o fato da matemática moderna ter se constituído historicamente na tentativa de construir fundamentos para a Análise (Respondente 5).

6. Defendendo o SIM, argumento que a matemática para um licenciando não deve ser de categoria inferior. Não me refiro apenas à informação e transmissão de conteúdos, mas à formação e à construção coletiva de ideias, conceitos, usos. Sei que cortes de Dedekind, por exemplo, não são simples, mas são necessários para que saibamos o quanto a matemática assume um caráter de aproximação, de verdade relativa, de aspectos formais (não no sentido de imutabilidade, mas no sentido subjetivo das "formas" em que se trabalham conceitos) (Respondente 6).

7. O aluno da licenciatura precisa conhecer a natureza do pensamento matemático. Essa disciplina é bem interessante para que o futuro professor conheça o espírito, digamos assim, da matemática, seus modos de proceder, suas demonstrações, a forma como a matemática organiza-se em conhecimento específico (Respondente 7).

\section{Categoria 2:}

A disciplina Análise Real traz ao licenciando uma fundamentação necessária a uma visão aprofundada do conhecimento matemático que se estuda na Educação Básica. Este conhecimento é necessário para que o futuro professor possa perceber problemas epistemológicos importantes nas abordagens usuais dadas a conceitos como números racionais e irracionais, sequências, funções, continuidade, entre outros. Permite ao futuro professor discutir de modo mais amplo o conhecimento que irá lecionar. Atuaria também na fundamentação da ênfase (maior ou menor) a ser dada ao ensino de certos tópicos.

Coincidentemente com o que corresponde à Categoria 1, oito educadores matemáticos (cerca de 60\% dos 13 que responderam) apresentaram argumentos nessa Categoria 2, totalizando oito unidades (40\%) das 20 selecionadas. Apresentamos, abaixo, algumas unidades que ilustram os argumentos nessa Categoria 2. 
1. Como as perguntas estão descontextualizadas, as respostas se referem a um curso ideal. Sem o que indiquei (construção dos reais a partir dos cortes, sequências de Cauchy ou intervalos encaixantes; teorema do valor intermediário tratado rigorosamente), o professor vai ensinar "números reais" sem ter a menor ideia do que sejam (Respondente 1).

2. Defendo que essa disciplina (que poderia ter até outro nome) deve fazer parte de cursos de formação para professores de matemática porque seria talvez a única oportunidade para os futuros professores refletirem a respeito desse ente tão familiar que é o número real. E entendendo isso, em sua prática talvez ele jamais tivesse dúvidas do tipo "0,999... = 1?" (Respondente 8).

3. [...] um bom entendimento a respeito dos números reais e funções é necessário e suficiente. A maneira com que isso deve ser trabalhado é que vai fazer a diferença. [...] Nessa abordagem, "brotam" as sequências de intervalos encaixantes, as de Cauchy, a representação decimal etc. [...] o que considero importante é a compreensão dos elementos que compõem esse conjunto tão trabalhado e ao mesmo tempo tão mal compreendido - o conjunto dos números reais (Respondente 8).

4. A disciplina Análise Real traz ao licenciando uma fundamentação necessária a uma visão mais aprofundada do conhecimento matemático que se estuda na Educação Básica. Esse conhecimento é necessário para perceber problemas epistemológicos importantes nas abordagens que se dá a conceitos como números racionais e irracionais, sequências, funções, continuidade, por exemplo (Respondente 9).

5. Maior ênfase ao desenvolvimento histórico, à construção dos números (principalmente dos números reais) e entendimentos sobre isto, visando o ensino de matemática básica (Respondente $10)$.

6. Os futuros professores de matemática precisam, para sua prática docente, de uma compreensão ampla dos números reais para quando forem ensinar os campos numéricos e discutir conceitos tais como números racionais, irracionais, densidade e continuidade com seus alunos (Respondente 13).

Para finalizar esta seção, comentamos brevemente duas unidades de discurso que não se enquadraram em nenhuma das duas categorias acima, mas que sugerem a consideração de aspectos interessantes ligados ao trabalho com a disciplina Análise Real. Observamos que essas duas unidades foram extraídas dos argumentos apresentados pelo mesmo respondente (Respondente 10). Eis as duas unidades:

a) Maior ênfase ao desenvolvimento histórico, à construção dos números (principalmente dos números reais) e entendimentos sobre isto, visando aplicações em outras ciências.

b) As outras disciplinas, como as de Cálculo Diferencial e Integral e de Fundamentos em Matemática, em geral, não aprofundam suficientemente estes tópicos citados. O aprofundamento de outros tópicos como continuidade uniforme, integrais etc. não deve ser obrigatório.

\section{Nossos comentários:}

A unidade a) acima constitui, curiosamente, a única referência, entre todos os respondentes, a aplicações dos conhecimentos matemáticos envolvidos nas possíveis propostas de ementa para a disciplina Análise Real. Isso é interessante, especialmente quando contrastamos com as respostas dadas pelos matemáticos, pois nesse caso uma parte significativa dos respondentes fizeram menção às aplicações, constituindo as respectivas unidades de discurso uma categoria à parte na argumentação em favor da obrigatoriedade da disciplina Análise Real no curso de Licenciatura em Matemática (cf. MOREIRA, CURY e VIANNA, 2005). 
$\mathrm{Na}$ unidade b), por outro lado, o mesmo Respondente 10 parece justificar a obrigatoriedade da disciplina no currículo de formação inicial do professor de Matemática, dentre outros argumentos alocados nas categorias descritas anteriormente, pela necessidade de aprofundamento dos tópicos que compõem a ementa, aprofundamento esse que não seria feito nas disciplinas de Cálculo ou Fundamentos. Entretanto, não oferece razões pelas quais esse tipo de aprofundamento deveria ser obrigatório no processo de formação inicial do professor.

\section{Discussão}

Um aspecto que chama atenção no que descrevemos na seção anterior é o fato de que, como no caso dos matemáticos, nenhum educador matemático defendeu a não obrigatoriedade da disciplina Análise Real no curso de Licenciatura em Matemática. Isso se conforma ao fato de que, em praticamente todos os currículos deste curso em vigência nas grandes universidades brasileiras atualmente, essa disciplina é obrigatória. Entretanto, contrasta com o fato de que o PROFMAT, por exemplo, um mestrado profissional proposto pela SBM, destinado exclusivamente a professores da Educação Básica, não tenha Análise Real como disciplina obrigatória, embora tenha Cálculo Diferencial e Integral.

Por outro lado, ainda que seja generalizada a sensação de que não há um consenso geral em torno do desenho da formação matemática na licenciatura em matemática, considerando os dois estudos (com matemáticos e com educadores matemáticos), tivemos um total de apenas cinco categorias de argumentos, todos em defesa da obrigatoriedade da disciplina Análise Real no curso de licenciatura, sendo que muitos dos respondentes apresentaram argumentos comuns a pelo menos duas dessas categorias. Assim, esse estudo dá sinais de que essa divergência não parece ser tão acentuada como se propaga, pelo menos no que se refere especificamente ao papel da disciplina Análise Real na licenciatura.

Para facilitar ao leitor o acompanhamento dos comentários que faremos a seguir sobre as aproximações e distanciamentos das visões dos matemáticos e dos educadores matemáticos sobre essa temática da pesquisa, relembramos a descrição de cada uma das cinco categorias obtidas nos dois estudos:

Categoria 1M (argumentos dos matemáticos): A disciplina deve ser obrigatória no curso de licenciatura porque se constitui em ocasião privilegiada para o aluno tomar contato com o que significa matemática e com as formas como os matemáticos pensam. Desenvolve o raciocínio lógico e a capacidade de "pensar matematicamente", proporcionando, também, maior maturidade intelectual ao aluno. 
O trabalho na disciplina abrange métodos, técnicas, estruturas, concepções e valores fundamentais da matemática, constituindo-se, assim, em uma introdução ao que se poderia chamar de "cultura matemática".

Categoria 2M (argumentos dos matemáticos): A disciplina proporciona uma compreensão sólida e profunda dos conceitos básicos da matemática escolar, explica os "porquês" e dá mais segurança ao futuro professor da escola. Proporciona a construção de uma visão integrada e logicamente consistente da matemática elementar, em substituição a uma visão que a concebe como um amontoado desconexo de fórmulas e regras.

Categoria 3M (argumentos dos matemáticos): A disciplina constitui, para o aluno, um espaço de percepção da matemática como um instrumento que permite um entendimento profundo de certos fenômenos naturais e que tem aplicações em outras ciências.

Categoria 1EM (argumentos dos educadores matemáticos): A disciplina deve ser obrigatória no curso de licenciatura porque ela é fundamental para que os licenciandos tenham um contato mínimo com a matemática superior, o que constitui um elemento central na construção de um ponto de vista sobre a matemática moderna. O aluno da licenciatura precisa conhecer a natureza do pensamento matemático, seus modos de proceder, suas demonstrações, a forma como a matemática organiza-se em conhecimento específico, precisa ter uma cultura matemática.

Categoria 2EM (argumentos dos educadores matemáticos): A disciplina Análise Real traz ao licenciando uma fundamentação necessária a uma visão aprofundada do conhecimento matemático que se estuda na Educação Básica. Este conhecimento é necessário para que o futuro professor possa perceber problemas epistemológicos importantes nas abordagens usuais dadas a conceitos como números racionais $e$ irracionais, sequências, funções, continuidade, entre outros. Permitiria ao futuro professor discutir de modo mais amplo o conhecimento que irá lecionar. Atuaria também na fundamentação da ênfase (maior ou menor) a ser dada ao ensino de certos tópicos.

Excetuando-se a Categoria 3M, que se refere a aplicações, não diretamente mencionadas pelos educadores matemáticos, as demais categorias correspondentes (1M e 1EM; 2M e 2EM) acabaram se aproximando bastante, embora (especialmente as duas primeiras) resguardem certas diferenças que não nos permitiram identificá-las, reduzindo tudo apenas às três categorias dos matemáticos. Destacamos a seguir algumas dessas diferenças e aproximações.

As categorias 1M e 1EM têm claramente algo em comum, que se refere essencialmente a compreender a "natureza do pensamento matemático", compreender "o que é a matemática", desenvolver uma "cultura matemática". Em Moreira, Cury e Vianna (2005), apresentamos, com o propósito de contribuir para o avanço do debate, alguns questionamentos a esses argumentos, situando-os no contexto de atuação profissional do 
professor, que se refere a uma instituição social particular, com finalidades, normas, cultura e valores diferenciados em relação aos correspondentes do contexto acadêmico. Remetemos o leitor interessado nessa discussão ao próprio texto de 2005, para maiores detalhes. Aqui, basicamente, o que achamos interessante destacar é que, em ambos os grupos profissionais que se expressam através dessas duas categorias de argumentos (1M e 1EM), parece predominar um ponto de vista acadêmico na concepção do que sejam "cultura matemática", "pensamento matemático" e "natureza do conhecimento matemático". Além disso, talvez como consequência da particularidade dessa perspectiva, não se indica claramente como esses elementos contribuiriam efetivamente para a prática concreta do professor de matemática da Educação Básica.

Assim, quando nos perguntamos qual seria o papel da disciplina Análise Real na preparação do futuro professor para o exercício da prática docente na escola, e contemplamos as respostas dos matemáticos e dos educadores matemáticos sintetizadas nas categorias $\mathbf{1 M}$ e 1EM, respectivamente, fomos levados à seguinte consideração: para ambos os grupos de profissionais, a Análise Real é importante na licenciatura porque dá ao professor a oportunidade de adquirir uma cultura matemática, de entender o que significa pensar matematicamente e de ter uma noção aprofundada da natureza do conhecimento matemático. Mas, por que o futuro professor da escola precisa adquirir essa cultura matemática que a Análise Real oportuniza? Por que precisa entender o que significa pensar matematicamente, segundo o desenvolvimento dessa disciplina o leva a entender? E por que, como futuro profissional docente da Educação Básica, ele precisa entender a natureza desse conhecimento matemático que a Análise Real lhe propõe?

Ao adentrar o terreno em que se movem as eventuais respostas a essas questões, pudemos perceber, nas unidades de discurso que compõem as categorias 1M e 1EM, algumas sutis diferenças na forma de destacar certos aspectos dos argumentos apresentados. Pensamos que as diferenças se tornam mais claras quando contrastamos algumas das unidades de discurso que compõem as respectivas categorias. Assim, cotejamos, abaixo, unidades de discurso constituintes, respectivamente, da Categoria 1EM e da Categoria 1M, seguindo-as de alguns comentários em que identificamos algumas dessas diferenças.

\section{Unidade de discurso (Categoria 1EM)}

A abordagem da Análise traz para o licenciando uma maneira de lidar com conhecimentos matemáticos, a meu ver, bem diferente daquela que lhe confere o Cálculo, e o tratamento concedido à matemática da Educação Básica. Acho essa experiência importante, se for proporcionada com essa perspectiva: a apropriação de um outro modo de matematicar - um 
modo de viver a cultura matemática acadêmica, destacando-se os valores que permeiam, sustentam e conferem sentido às decisões que se tomam na configuração das elaborações $e$ procedimentos nesse campo, inclusive em comparação com outras possibilidades de abordagem.

\section{Unidade de discurso (Categoria 1M)}

A razão principal é que a experiência mostra que o fundamental para um professor não é saber grande quantidade de matemática, mas ter o pensamento matemático desenvolvido. Para isto ele deve obter maturidade matemática no seu curso de graduação. Precisa: saber pensar matematicamente. [...] A disciplina de Análise Real é aquela que mais desenvolve isto. O aluno que a faz atinge um outro patamar do seu desenvolvimento intelectual, na sua capacidade de análise de resolução de problemas. Um formando em licenciatura em matemática que não sabe pensar matematicamente da maneira correta é um desastre!!!

Observa-se a valorização absoluta do pensar matematicamente "da maneira correta" presente numa das unidades de discurso citadas, em contraste com a relativização que se desenha na outra: a condição que conferiria importância a isso na formação do professor seria a perspectiva segundo a qual a disciplina fosse trabalhada, ou seja, a disciplina deveria visar a apropriação de "um outro modo de matematicar", de viver a cultura matemática acadêmica, inclusive em comparação com outras possibilidades de abordagem (grifo nosso).

\section{Unidades de discurso (Categoria 1EM)}

a) Conceitos formais em um curso de Licenciatura deveriam ser apresentados de modo a expor sua necessidade ou propósito na construção do conhecimento matemático, seu poder e limitações. Penso em uma espécie de "meta-curso", as atividades a serem desenvolvidas deveriam ser diferentes daquelas desenvolvidas para um curso de bacharelado, uma vez que os motivos para a apresentação das ferramentas matemáticas seriam diferentes.

b) Acho fundamental para a apropriação de uma cultura matemática que o aluno tenha uma boa formação em Análise. A disciplina, em geral, é muito exigente, pois lida com grandes rupturas no pensamento matemático. Isso a meu ver é inevitável, pois sua raiz é epistemológica. Não é a toa que a formalização dos números reais, das noções de função, continuidade e limite exigiram tanto tempo na própria história da matemática.

c) Um bom curso de análise na licenciatura deveria, na minha opinião, permitir aos alunos enfrentar essa ruptura, tomar consciência desse enfrentamento e refletir sobre como preparar o terreno para que os alunos do Ensino Médio possam também viver esse processo. Por isso, eu incluiria os itens relativos às notas históricas (o que permitiria ao aluno perceber que o processo vivido por ele não é pessoal apenas, mas fruto da natureza do conhecimento com o qual está lidando).

\section{Unidades de discurso (Categoria 1M)}

a) $O$ professor precisa conhecer as principais estruturas matemáticas. Assim, entender a estrutura de corpo ordenado completo da reta e as propriedades decorrentes desta estrutura, a formalização dos conceitos de função contínua e função diferenciável, bem como o entendimento da estrutura matemática que os espaços euclidianos 
possuem, que permite que nesses espaços sejam definidas e tomem valores as funções contínuas e diferenciáveis. Como diz o Prof. Geraldo Ávila em seu livro, "Enunciar e demonstrar teoremas é uma das ocupações centrais de todo professor ou estudioso da matemática, não sendo admissível que alguém que pretende ensinar matemática sinta-se deficiente nesse mister".

b) Arcabouço do pensamento matemático. Curso onde se aprende a concepção da ciência matemática: o significado dos axiomas e o conceito de prova.

c) Ela representa uma boa oportunidade para o aluno entender conceitos básicos importantes tais como indução matemática, e uma boa introdução a um nível mais abstrato e potente. Além disso, é um bom cenário para que o aluno entenda o que é uma demonstração matemática feita com rigor.

Observa-se, mais uma vez, algumas diferenças entre os argumentos dos educadores matemáticos e os dos matemáticos, embora estejam defendendo, igualmente, a obrigatoriedade da disciplina na formação do professor da Educação Básica e, essencialmente, pelas mesmas razões (a necessidade que o professor da escola teria de conhecer certos conceitos, métodos, técnicas, estruturas e valores matemáticos, de um ponto de vista acadêmico ou seja, da forma como os matemáticos profissionais a conhecem). Entretanto, nos argumentos dos educadores matemáticos, está sempre presente alguma preocupação com a aprendizagem e com a forma de trabalhar a disciplina no curso de licenciatura (a explicitação das necessidades e do propósito de ensinar os conceitos formais, o recurso à história, a atenção com uma possível ruptura epistemológica e seu impacto na forma de pensar do licenciando, ao lidar com a abstração, o rigor e o formalismo de que se revestem os conceitos trabalhados na disciplina, o possível reflexo dessa experiência de aprendizagem matemática na ação pedagógica do professor no Ensino Médio etc.). Para os matemáticos, de modo geral, observa-se a ênfase no que deve ser ensinado e no que esse ensino, uma vez realizado, geraria na visão sobre a matemática do futuro professor da escola.

Com relação às categorias $\mathbf{2 M}$ e $\mathbf{2 E M}$, as diferenças, a nosso ver, se desvanecem. Basicamente, o que se entende, tanto no caso dos matemáticos como no caso dos educadores matemáticos participantes dos nossos estudos, é que a disciplina Análise Real, segundo as ementas propostas pelos respondentes e utilizando as referências bibliográficas indicadas por eles neste artigo e em Moreira, Cury e Vianna (2005), permitiria ao professor olhar para os conceitos, técnicas, processos e métodos trabalhados na matemática da escola básica com a segurança de quem sabe "o que são". Possibilitaria um olhar "de cima”, que, supostamente, daria segurança ao professor. O pressuposto aí, em ambos os grupos profissionais, é o de que o futuro professor da Educação Básica, se não tem um domínio completo (conceitual e procedimental) do que vai ensinar, poderia vir a tê-lo com a ajuda dos conhecimentos, 
conceitos, técnicas, métodos e processos matemáticos veiculados na disciplina Análise Real, ou seja, a partir da aquisição de um ponto de vista formal, rigoroso, abstrato, especialmente sobre o conjunto dos números reais, como o que seria trabalhado nesta disciplina, de acordo com a ementa e bibliografia propostas pelos respondentes em cada um dos estudos que fizemos. No caso do artigo de 2005, várias vezes aqui referido, colocamos em discussão essa visão do papel da Análise Real no curso de Licenciatura. Remetemos, então, o leitor interessado em mais detalhes desse questionamento ao próprio artigo ou a Moreira e David (2008).

Embora desde o primeiro estudo (2005), infelizmente, não tenha havido, até onde tomamos conhecimento, grande avanço nos estudos científicos empíricos sobre o papel da matemática acadêmica, em geral, na formação do professor da Educação Básica, é interessante acrescentar à discussão que desenvolvemos na época, breves comentários sobre um estudo nessa direção, que veio a público há cerca de seis anos (Zazkis \& Leikin, 2010). Nesse trabalho, relata-se a opinião de 52 professores israelenses, do estágio escolar correspondente ao Ensino Médio brasileiro, sobre o uso que fazem, nas suas respectivas práticas docentes, da matemática que aprendem nos cursos de formação universitária (correspondentes, em princípio, às nossas licenciaturas).

As autoras chamam atenção para o seguinte: a maioria dos professores entrevistados afirma que, em geral, esses conhecimentos matemáticos "avançados" lhes dão confiança e segurança no trabalho docente, além de facilitar o estabelecimento de conexões entre os temas que ensinam e ajudar a produzir respostas para algumas perguntas dos alunos. Entretanto, muito poucos conseguiram dar exemplos específicos e concretos de situações em que fizeram uso da matemática avançada no sentido que descreveram. E os poucos que conseguiram, referiram-se basicamente ao Cálculo Diferencial (que é trabalhado por alguns dos entrevistados no Ensino Médio), Estatística, Matrizes e Sistemas Lineares, Teoria dos Números e Combinatória, e, muitas vezes, abordando questões extracurriculares. Observamos, de passagem, que nenhum deles mencionou nada relativo à Análise Real.

De todo modo, é prudente observar certos pontos em relação a esse estudo específico, aguardando outros similares que venham a constituir massa crítica suficiente para que possamos chegar a resultados mais conclusivos e confiáveis. Em primeiro lugar, a questão da confiança e segurança que o professor percebe como resultado do domínio dos conhecimentos matemáticos avançados se refere basicamente a uma sensação subjetiva, embora encontre certa objetividade no fato de que esse conhecimento avançado é muito mais valorizado socialmente do que o conhecimento matemático escolar. Assim, é perfeitamente 
compreensível que venha a conferir tal sensação de segurança a quem o domina, ainda mais que o senso comum a respeito do saber profissional docente reza como primeiro mandamento que para ensinar matemática é necessário saber matemática (e pela hierarquização, sabendo a avançada, saber-se-ia a elementar, ou seja a escolar). Apenas em segundo, ou terceiro lugar, viria a ideia, ainda simplista e retratando uma visão bastante superada na comunidade dos educadores matemáticos, do trabalho docente escolar em matemática, a de que é também necessário "saber transmitir".

Quanto às conexões entre os temas, a questão também precisa, a nosso ver, sair do lugar comum e ser aprofundada na seguinte direção: quais conexões são relevantes para o trabalho docente escolar? Serão as (poucas) descritas pelos entrevistados relevantes para a formação matemática escolar? É claro que conceitos como o de anel euclidiano unificam e conectam, por exemplo, a estrutura do conjunto dos números inteiros e a do conjunto dos polinômios com coeficientes em $\mathrm{Q}$ ou em $\mathrm{R}$, mas em que sentido perceber essas conexões ajuda, precisa e concretamente, a prática docente na sala de aula da escola, ambiente no qual os números inteiros são objetos totalmente distintos dos polinômios? Por fim, quanto à questão da produção de respostas para as perguntas dos alunos, de novo, é preciso sair da subjetividade da visão do professor que respondeu e saber se não haveria modos de produzir respostas pedagogicamente mais "eficientes" para as mesmas perguntas dos alunos, a partir de outro tipo de conhecimento matemático, como aquele que se situa na interface da matemática e da relação dos estudantes com ela (Knowledge of Content and Students - KCS - na linguagem de BALL, THAMES e PHELPS, 2008) do que buscar essas respostas em um tipo de conhecimento produzido a partir de abstrações e formalismos, muitas vezes inacessíveis ao estágio escolar da aprendizagem matemática.

Entendemos que não foi por acaso que os professores participantes do estudo de Zazkis e Leikin (2010) tiveram dificuldade de produzir exemplos concretos de situações em que uma forma específica do conhecimento matemático avançado pudesse ajudá-los na prática pedagógica. A ideia de que a matemática universitária ajuda na execução da prática docente na escola é parte do senso comum, no plano do imaginário e, muitas vezes se traduz no refrão: "saber, quanto mais melhor". É interessante observar, neste sentido, que Zazkis e Leikin relatam o caso de um professor que disse que não passava um dia em sua prática em que não utilizava o conhecimento matemático que aprendeu na universidade, mas instado a dar exemplos concretos de situações em que os usou efetivamente, não conseguiu apresentar nenhum. Isso parece apoiar a ideia de que o efeito da confiança e segurança pode não ter base objetiva de peso. 
Sintetizando, entendemos que as decisões curriculares, embora girem naturalmente em torno do confronto de opiniões e visões pessoais, precisam ser defendidas e contraditadas com fundamento em estudos científicos, pois o tempo de formação é curto, os saberes associados às questões que se colocam na prática docente escolar são muitos e escolhas prudentes precisam ser feitas.

\section{Considerações finais}

Nesta segunda parte de um projeto que procura conhecer a visão de matemáticos, de educadores matemáticos e de professores de matemática da Educação Básica a respeito do papel da disciplina Análise Real na formação do professor em cursos de Licenciatura, colocamos em discussão a visão dos educadores matemáticos. Na primeira parte desse projeto, num artigo que veio a público em 2005, relatamos a visão dos matemáticos. Apesar de notórias diferenças na concepção geral do processo de formação de professores, expressas em várias instâncias, gerando polêmicas públicas entre matemáticos e educadores matemáticos, no que se refere especificamente ao papel da disciplina Análise Real na formação do professor pudemos constatar uma aproximação surpreendente entre as visões desses dois grupos de profissionais, tomando por base aqueles que participaram da nossa pesquisa. Sumarizando, não houve discordância quanto à obrigatoriedade dessa disciplina no currículo da licenciatura em matemática. As divergências se centraram essencialmente no modo de abordar alguns tópicos, sobre a presença dos quais, na ementa da disciplina, não houve discordâncias significativas. Os livros mais indicados como possível referência bibliográfica básica para a disciplina foram, por parte dos matemáticos, Análise I (Djairo), Análise Real (Elon) e Introdução à Análise Matemática (Ávila) com, respectivamente, em torno de $60 \%, 40 \%$ e $30 \%$ de indicações. E, por parte dos educadores matemáticos, Análise Matemática para a Licenciatura (Ávila) e Análise I (Djairo), com respectivamente, 66\% e $11 \%$ de indicações.

Quanto aos argumentos que fundamentam a visão de que essa disciplina deva ser obrigatória na formação inicial do professor de matemática da Educação Básica, temos o seguinte paralelo, em termos gerais: no caso dos educadores matemáticos, esses argumentos vieram a compor duas categorias e no caso dos matemáticos, três. A terceira categoria dos matemáticos referia-se a aplicações da matemática, em que os conceitos e métodos da disciplina em questão estariam presentes. Apenas um dos educadores matemáticos mencionou esse argumento, por isso não chegamos a criar uma categoria equivalente para esse grupo 
profissional. As duas primeiras categorias de argumentos dos dois grupos foram muito próximas, com nuances que as diferenciaram.

Basicamente, ambos os grupos consideram que a disciplina Análise na Reta deve ser obrigatória no curso de licenciatura porque ela é fundamental para que os licenciandos tenham um contato mínimo com a matemática superior e possam construir um ponto de vista sobre a matemática atual. Além disso, o aluno da licenciatura precisa conhecer a natureza do pensamento matemático, a forma como a matemática organiza-se em conhecimento específico, precisa ter uma cultura matemática (Primeira Categoria). Num segundo conjunto de argumentos, ambos os grupos defendem a obrigatoriedade da disciplina na licenciatura porque ela traria um aprofundamento dos conhecimentos matemáticos ao licenciando. Este conhecimento seria necessário para que o futuro professor pudesse perceber problemas epistemológicos importantes nas abordagens usuais dadas a conceitos como números racionais e irracionais, funções, continuidade etc. e permitiria ao futuro professor discutir de modo mais amplo o conhecimento que irá lecionar (Categoria 2).

A essa altura, é preciso lembrar, mais uma vez, que esta pesquisa tem um caráter exploratório e, como enfatizamos desde o início, seus resultados não podem ser generalizados para toda a comunidade brasileira dos matemáticos ou dos educadores matemáticos. No entanto, achamos que tanto as diferenças quanto as proximidades observadas nos argumentos priorizados por cada um desses dois grupos de profissionais em suas respostas às nossas perguntas remetem a reflexões potencialmente interessantes sobre a estrutura geral do curso de licenciatura em matemática. Para destacar um exemplo, poderíamos tentar entender o seguinte ponto: como essas aproximações e diferenças se refletem no caminho da construção de uma superação real e efetiva da estrutura " $3+1$ ”, tão combatida, mas ainda fundamentalmente se impondo sobre as licenciaturas brasileiras? Outra questão que merece consideração: como essas aproximações e diferenças se refletem na concepção de uma forma, alternativa à axiomática tradicional, de organização e sistematização do conhecimento matemático específico para o ensino, a fim de viabilizar a produção de textos didáticos especialmente produzidos para a formação matemática do professor da Educação Básica, ao invés de tomá-los emprestados da formação do matemático nos cursos de bacharelado, como é o caso dos textos utilizados comumente na disciplina Análise na Reta na licenciatura? Há muitas outras questões interessantes para as quais poderíamos ser remetidos, a partir deste estudo, mas deixemos que o debate prossiga na direção que cada leitor queira imprimir ao relato que aqui apresentamos. De todo modo, renovamos a promessa de, num trabalho futuro, 
coletar e trazer para o debate a visão dos professores em exercício da prática docente escolar e dos licenciandos.

\section{Referências}

BALL, D. L.; THAMES, M. H.; PHELPS, G. Content knowledge for teaching: What makes it special? Journal of Teacher Education, East Lansing, MI, v. 59 (5), p. 389-407, 2008.

BARDIN, L. Análise de Conteúdo. Lisboa: Edições 70, 1979.

MOREIRA, P. C.; CURY, H. N.; VIANNA, C. R. Por que análise real na Licenciatura? Zetetiké, Campinas, SP, v.13, n. 23, p. 11-42, jan./jun. 2005.

MOREIRA, P. C.; DAVID, M. M. M. S. Academic mathematics and mathematical knowledge needed in school teaching practice: Some conflicting elements. Journal of Mathematics Teacher

Education, New York, NY, v. 11, 23-40, 2008.

SHULMAN, L. S. Those who understand: knowledge growth in teaching. Educational Researcher, Thousand Oaks, CA v. 15, n. 2, p. 4-14, 1986.

SHULMAN, L. S. Knowledge and teaching: Foundations of the new reform. Harvard Educational Review, [Cambridge, MA] v. 57, p. 1-22, 1987.

TARDIF, M. Saberes docentes e formação profissional. Petrópolis: Vozes, 2002.

ZAZKIS, R.; LEIKIN, R. Advanced Mathematical Knowledge in Teaching Practice: Perceptions of Secondary Mathematics Teachers. Mathematical Thinking and Learning, Mahwah, NJ, v. 12 (4), p. 263-281, 2010.

Submetido em Abril de 2015. Aprovado em Junho de 2015. 